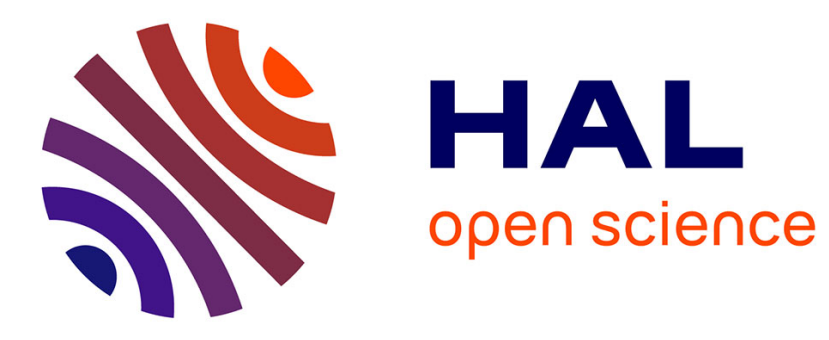

\title{
Highly Efficient Access to Original Polycyclic Pyrrolopiperazine Scaffolds by a Three-Component Reaction with 1,3-Dicarbonyls.
}

Frédéric Liéby-Müller, Thierry Constantieux, Jean Rodriguez

\section{- To cite this version:}

Frédéric Liéby-Müller, Thierry Constantieux, Jean Rodriguez. Highly Efficient Access to Original Polycyclic Pyrrolopiperazine Scaffolds by a Three-Component Reaction with 1,3-Dicarbonyls.. SYNLETT, 2007, pp.1323-1325. 10.1055/s-2007-973906 . hal-00681078

\section{HAL Id: hal-00681078 https://hal.science/hal-00681078}

Submitted on 20 Mar 2012

HAL is a multi-disciplinary open access archive for the deposit and dissemination of scientific research documents, whether they are published or not. The documents may come from teaching and research institutions in France or abroad, or from public or private research centers.
L'archive ouverte pluridisciplinaire HAL, est destinée au dépôt et à la diffusion de documents scientifiques de niveau recherche, publiés ou non, émanant des établissements d'enseignement et de recherche français ou étrangers, des laboratoires publics ou privés. 


\section{Highly Efficient Access to Original Polycyclic Pyrrolopiperazine Scaffolds by Three-Component Reaction with 1,3-Dicarbonyls}

Frédéric Liéby-Muller, Thierry Constantieux* and Jean Rodriguez*

Université Paul Cézanne (Aix-Marseille III) - CNRS UMR 6178 «SYMBIO » - Faculté des Sciences et Techniques - Case 531 - 13397 MARSEILLE Cedex 20, France

Fax: +33-(0)491-288-841

E-mail: jean.rodriguez@univ-cezanne.fr

\begin{abstract}
Molecular sieves have been found to promote a new fast, environmentally friendly and experimentally simple multicomponent domino reaction from 1,3-dicarbonyls for the synthesis of pyrrolopiperazine and azasteroid-like scaffolds, of potential synthetic and biological interests.
\end{abstract}

Key words: multicomponent reaction, atom economy, pyrrolopiperazine, 1,3-dicarbonyls, molecular sieves, heterogeneous catalysis.

In modern organic chemistry, the development of new, rapid, selective, environmentally friendly, ${ }^{1}$ step- and atom-economical ${ }^{2}$ synthetic routes toward focused libraries of functionalized heterocyclic building blocks is of great importance to both medicinal and synthetic chemists, and still constitutes a challenge from academic and industrial points of view. ${ }^{3}$ Although the "ideal synthesis" is unlikely to be achieved routinely, multicomponent reactions ${ }^{5}$ (MCRs) involving domino processes, ${ }^{6}$ with at least three different simple substrates reacting in a well-defined manner to form a single compound, emerged as a powerful tool in target-oriented synthesis. ${ }^{7}$ In addition, these transformations can be efficiently mediated by heterogeneous catalysts, making this process nearly ideal in terms of both greenness and simplicity. ${ }^{8}$ Herein we present the direct, high-yielding one-pot conversion of simple 1,3-dicarbonyl compounds ${ }^{9} \mathbf{1}$ into pyrrolopiperazine scaffolds 4 promoted by $4 \AA$ molecular sieves (MS). The presence of the 1,2,3,4tetrahydropyrrolo[1,2-a]pyrazine core ${ }^{10}$ is of interest for both biological and synthetic purposes. Compounds with a related structure are found in some families of naturally occurring marine alkaloids which have been the centre of much recent attention. ${ }^{11}$ Alternatively, related synthetic pyrazine nuclei are known to present a large spectrum of biological activities. ${ }^{12}$

The success of our approach is based on the production, under heterogeneous catalysis by MS, of functionalised iminium ions and their selective in situ trapping. ${ }^{13}$ Following this concept, we have now designed a new domino reaction forming two C-C bonds from 1,3dicarbonyl 1, a Michael acceptor 2 and a functionalized pyrrole 3. As outlined in scheme 1, the sequence involves four different reactions in an ordered manner i.e. Michael addition, aldimine formation, nucleophilic addition leading to an ene-iminium intermediate, and a Pictet-Spengler-type cyclisation. ${ }^{14}$ This new operationally simple strategy is amenable to the highly efficient onepot construction of pyrrolopiperazine scaffolds of type 4 .

The scope of this novel MCR was examined using various acyclic and cyclic 1,3-dicarbonyls (1a-i, Scheme 2). According to our designed strategy, a range of poly- heterocyclic compounds were synthesized in good to excellent yields (4a-i, Scheme 3 ) by simply heating a toluene solution of 1,3-dicarbonyl compound $\mathbf{1}$, acrolein 2 and 1-(2-aminoethyl)-pyrrole ${ }^{15} \mathbf{3}$, in the presence of $4 \AA \mathrm{MS}$.
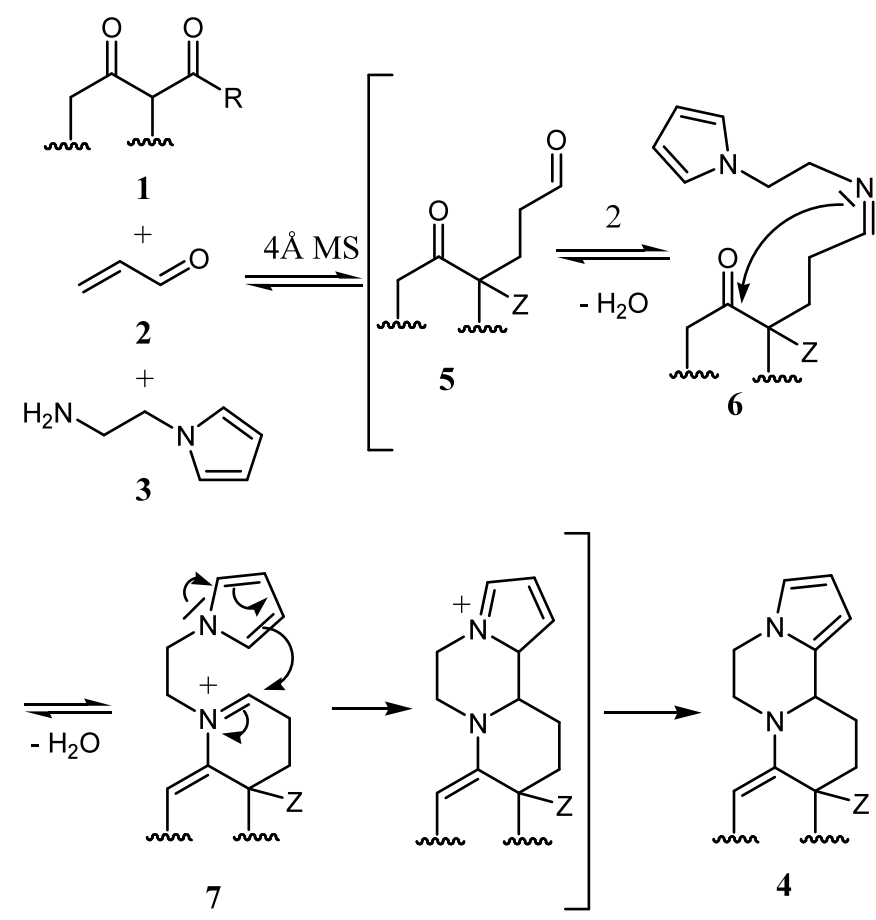

Scheme 1<smiles>[R]C(=O)CC([R])=O</smiles><smiles></smiles>

1a: $\mathrm{R}^{1}=\mathrm{Me}, \mathrm{R}^{2}=\mathrm{OEt}$ 1b: $R^{1}=E t, R^{2}=O M e$ 1c: $\mathrm{R}^{1}=\mathrm{Ph}, \mathrm{R}^{2}=\mathrm{OMe}$ 1d: $R^{1}=R^{2}=M e$

1e: $\mathrm{n}=0, \mathrm{X}=\mathrm{CH}_{2}, \mathrm{R}=\mathrm{Me}$

1f: $\mathrm{n}=1, \mathrm{X}=\mathrm{CH}_{2}, \mathrm{R}=\mathrm{Et}$

1g: $\mathrm{n}=1, \mathrm{X}=\mathrm{S}, \mathrm{R}=\mathrm{Et}$

1h: $\mathrm{n}=1, \mathrm{X}=\mathrm{NBn}, \mathrm{R}=\mathrm{Et}$

1i:

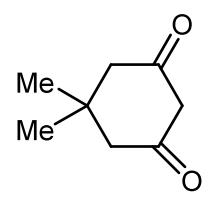

\section{Scheme 2}

Under these neutral heterogeneous conditions, the overall sequence proved to be of general applicability 
and products 4 were obtained, by a simple filtration through a short pad of Celite, with generally very high chemical purity. ${ }^{16}$<smiles>[R]C(=O)C1=C([R])N2CCn3cccc3C2CC1</smiles>

4a: $\mathrm{R}^{1}=\mathrm{Me}, \mathrm{R}^{2}=\mathrm{OEt}, 80 \%$

4c: $\mathrm{R}^{1}=\mathrm{Ph}, \mathrm{R}^{2}=\mathrm{OEt}, 82 \%$

4d: $\mathrm{R}^{1}=\mathrm{R}^{2}=\mathrm{Me}, 94 \%$ 4b: $R^{1}=E t, R^{2}=$ OMe, $92 \%$<smiles>CC1(C)CC(=O)C2=C(C1)N1CCn3cccc3C1CC2</smiles>

4i: $90 \%$<smiles>[Y]C1=CCC=C2N3CCn4cccc4[C@H]3CC[C@]12C(=O)O</smiles>

4e: $\mathrm{n}=0, \mathrm{X}=\mathrm{CH}_{2}, \mathrm{R}=\mathrm{Me}, 83 \%$ (trans $/$ cis: 1$)$

4f: $\mathrm{n}=1, \mathrm{X}=\mathrm{CH}_{2}, \mathrm{R}=\mathrm{Et}, 82 \%$ (trans $/$ cis: 1 )

4g: $\mathrm{n}=1, \mathrm{X}=\mathrm{S}, \mathrm{R}=\mathrm{Et}, 77 \%$ (trans/cis: 2 )

4h: $\mathrm{n}=1, \mathrm{X}=\mathrm{NBn}, \mathrm{R}=\mathrm{Et}, \mathbf{9 8 \%}$ (trans only)

\section{Scheme 3}

All the products are highly functionalized scaffolds which present many synthetic opportunities. Acyclic $\beta$ ketoesters 1a-c or $\beta$-diketone 1d led to the formation of tricyclic derivatives 4a-d in very good yields (Scheme 3 ), and cyclic $\beta$-ketoesters 1e-g gave the expected tetracyclic analogues obtained as a mixture of two diastereomers, in which prevails a 1,4-trans relationship between the ester function and the proton of the piperazine ring junction. ${ }^{17}$ In this latter case, the sequence afforded products with a steroid-like skeleton, bearing two (4f) or three $(\mathbf{4 h})$ nitrogen atoms starting from six-membered ring $\beta$-ketoesters $\mathbf{1 f}$ or $\mathbf{1 h}$. Introduction of other heteroatom such as sulfur was also possible. Indeed, $\beta$-ketoester $1 \mathrm{~g}$ gave tetracyclic compound $\mathbf{4 g}$ in $77 \%$ yield as a mixture of two diastereomers in a 2:1 trans:cis ratio. Interestingly enough, piperidone $\mathbf{1 h}$, gave the expected product $\mathbf{4 h}$ as a single 1,4-trans diastereomer in $98 \%$ yield. $^{18}$ Although NMR analysis ${ }^{17}$ was in agreement with the proposed structure, we were able to obtain single crystals by slow evaporation of the solvent, which allowed its study by X-ray diffraction (Figure 1$)^{19}$ and unequivocally established the structural elucidation and the relative 1,4-trans stereochemistry. Finally, cyclic 1,3diketone 1i led also to the expected tetracyclic azasteroid-like product $4 \mathbf{i}$ in good yield.
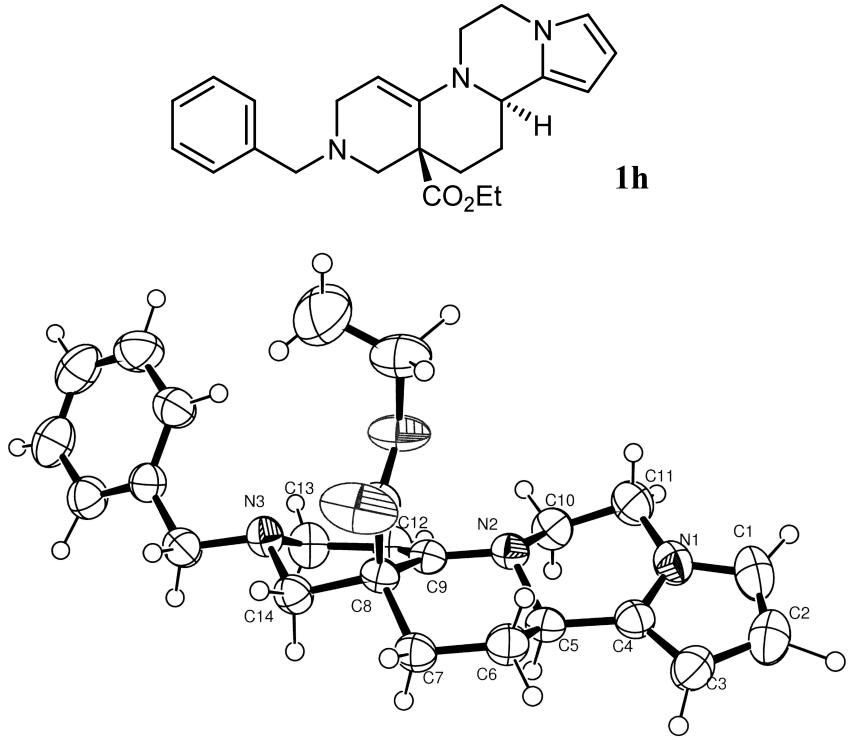

Figure 1

From a mechanistic point of view, various reaction pathways are possible by mixing the three starting materials. However, based on the successful reactivity of independently prepared Michael adduct $5 \mathbf{h}$ towards 1-(2aminoethyl)-pyrrole ${ }^{15} \mathbf{3}$ under the standard reaction conditions, we may consider that the first step of the sequence is a MS promoted Michael addition of the 1,3dicarbonyl compounds with acrolein to give adducts $\mathbf{5}$ (Scheme 1). ${ }^{20}$ Then, the formation of the ene-iminium intermediate 7 may occur via nucleophilic addition of the corresponding aldimine $\mathbf{6}$, followed by the terminal Pictet-Spengler-type cyclisation to provide, after rearomatisation, the final product 4 . Thus, the formation of one single compound is observed during this new multicomponent domino reaction which constitutes the first highly efficient one-pot route to piperazine scaffolds having an azasteroid-type ${ }^{21}$ core. The sequence involves formation of two new cycles, five novel bonds including two C-C bonds, and up to four stereogenic centers from simple achiral substrates. Moreover, water is the only byproduct and is easily trapped in situ by MS, which not only act as dehydrating agent, but also as heterogeneous catalyst for the Michael addition. ${ }^{22}$

In conclusion, we present a novel fast, environmentally friendly and experimentally simple multicomponent domino reaction for the synthesis of polyheterocyclic structures of potential synthetic and biological interests. To our knowledge, this strategy constitutes the first direct one-pot access to pyrrolopiperazine and azasteroidtype scaffolds, from simple and readily accessible substrates. The sequence does not require any harmful reagents, and liberates water as the only by-product. This novel methodology involving heterogeneous catalysis by $4 \AA$ MS should be a good complement in the field of heterocyclic chemistry. 


\section{Ackowledgment.}

We would like to thank the CNRS and the Conseil Régional PACA for providing a doctoral fellowship to F. LM. We are also particularly grateful to Dr. Hugues Bienaymé (Pierre Fabre Urologie) for his support and fruitful discussions, to Dr. M. Giorgi for X-rays analysis and Dr. R. Faure for NMR analysis and interpretations.

\section{References}

(1) For a special issue in environmental chemistry, see Chem Rev. 1995, 95, 3.

(2) Trost, B. M. Acc. Chem. Res. 2002, 35, 695.

(3) Weber, L.; Illgen, M.; Almstetter, M. Synlett 1999, 366.

(4) Wender, P. A.; Handy, S. T.; Wright, D. L. Chem. Ind. 1997, 19, 765 .

(5) (a) Multicomponent Reactions, Zhu, J.; Bienaymé, H., Eds., Wiley-VCH: Weinheim, 2005. (b) Ramon, D. J.; Yus, M. Angew. Chem., Int. Ed. 2005, 44, 1602; (c) Dömling, A. Chem. Rev. 2006, 106, 17.

(6) (a) Domino Reactions in Organic Synthesis, Tietze, L. F.; Brasche, G.; Gericke, K. M., Wiley-VCH: Weinheim, 2006; For some representative reviews, see: (b) Tietze, L. F.; Lieb, M. E. Curr. Op. Chem. Biol. 1998, 2, 363. (c) Rodriguez, J. Synlett 1999, 505.

(7) (a) Schreiber, S. L. Science 2000, 287, 1964. (b) Wender, P. A.; Gamber, G. G.; Hubbard, R. D.; Pham, S. M.; Zhang, L. J. Am. Chem. Soc. 2005, 127, 2836; (c) Vugts, D. J.; Koningstein, M. M.; Schmitz, R. F.; de Kanter, F. J. J. ; Groen, M. B. ; Orru, R. V. A. Chem. Eur. J. 2006, 12, 7178.

(8) Tucker, J. L. Organic Process Research \& Development 2006, 10, 315

(9) For recent reviews on the utilization of 1,3-dicarbonyl derivatives in MCRs, see: (a) Simon, C.; Constantieux, T.; Rodriguez, J. Eur. J. Org. Chem. 2004, 4957. (b) LiébyMuller, F. ; Simon, C. ; Constantieux, T. ; Rodriguez, J. QSAR Comb. Sci. 2006, 25, 432.

(10) (a) Peresada, V. P.; Medvedev, O. S.; Likhosherstov, A. M.; Skoldinov, A. P. Khim. Farm. Zh. 1987, 21, 1054. (b) Katritzky, A. R.; Jain, R.; Xu, Y.-J.; Seel, P. J. J. Org. Chem. 2002, 67, 8220.

(11) (a) For a recent review, see: Hoffmann, H.; Lindel, T. Synthesis 2003, 1753. see also: (b) Davis, F. A.; Deng, J. Org. Lett. 2005, 7, 621.

(12) (a) Seredenin, S. B.; Voronina, T. A.; Likhosherstov, A. M.; Peresada, V. P.; Molodavkin, G. L., Halikas, J. A. US 5,378,846, 1995. (b) Negoro, T.; Murata, M.; Ueda, S.; Fujitani, B.; Ono, Y.; Kuromiya, A.; Komiya, M.; Suzuki, K.; Matsumoto, J. J. Med. Chem. 1998, 41, 4118.

(13) (a) Simon, C.; Peyronel, J.F.; Rodriguez, J. Org. Lett. 2001, 3, 2145; (b) Simon, C.; Liéby-Muller, F.; Peyronel, J.-F.; Constantieux, T.; Rodriguez, J. Synlett 2003, 2301; (c) Liéby-Muller, F. ; Constantieux, T. ; Rodriguez, J. J. Am. Chem. Soc. 2005, 127, 17176. (d) Liéby-Muller, F.; Simon, C. ; Imhof, K. ; Constantieux, T. ; Rodriguez J. Synlett 2006, 1671.

(14) (a) Pictet, A.; Spengler, T. Ber. Dtsch. Chem. Ges. 1911, 44, 2030. (b) For a review, see Cox, E. D.; Cook, J. M. Chem. Rev. 1995, 95, 1797.

(15) Jirkovsky, I.; Baudy, R. Synthesis 1981, 481.

(16) Typical Procedure for the synthesis of compounds 4: To a $50 \mathrm{~mL}$ two-necked round bottomed flask flushed with Ar, equipped with a magnetic stirring bar and a reflux condenser, were added toluene freshly distilled over $\mathrm{CaH}_{2}(25$ $\mathrm{mL})$, commercially available inactivated $4 \AA \mathrm{MS}(6 \mathrm{~g}), \beta$ ketoester 1 (200 mg, 1.0 equiv.), freshly distilled acrolein 2
(1.2 equiv.), and amine 3 (1.0 equiv.). The heterogeneous mixture was stirred at reflux under Ar for $24 \mathrm{~h}$. The solution was filtered through a short pad of Celite, which was thoroughly washed with toluene. The solvent was evaporated under reduced pressure to afford crude compound $\mathbf{4}$ with good chemical purity. An analytical sample was isolated by flash chromatography over silica gel. Selected physical data for compounds $4 \mathrm{~h}$ : yellow oil; $\mathrm{Rf}=0.57$ (Petroleum ethers/AcOEt 3:1); IR (Liquid film) v 2924, 1735, 1654, $1156,1094 \mathrm{~cm}^{-1}$; MS (ESI) $\mathrm{m} / \mathrm{z}$ [relative intensity (\%)] : $392[\mathrm{M}+\mathrm{H}]^{+}$(13.0), 273 (100), 120 (10.7); ${ }^{1} \mathrm{H}$ NMR $\left(\mathrm{CDCl}_{3}, 300.13 \mathrm{MHz}\right) \delta 7.23(5 \mathrm{H}, \mathrm{m}), 6.50(1 \mathrm{H}, \mathrm{m}), 6.16$ $(1 \mathrm{H}, \mathrm{dd}, J=3.6 \mathrm{~Hz}, J=2.7 \mathrm{~Hz}), 5.85(1 \mathrm{H}, \mathrm{t}, J=1.5 \mathrm{~Hz})$, $4.90(1 \mathrm{H}, \mathrm{dd}, J=4.7 \mathrm{~Hz}, J=2.1 \mathrm{~Hz}), 4.10(2 \mathrm{H}, \mathrm{m}), 4.03$ $(1 \mathrm{H}, \mathrm{m}), 3.94(1 \mathrm{H}$, broad dd, $J=11.6 \mathrm{~Hz}, J=3.0 \mathrm{~Hz}), 3.68$ $(1 \mathrm{H}, \mathrm{d}, J=13.3 \mathrm{~Hz}), 3.58(1 \mathrm{H}, \mathrm{dd}, J=11.6 \mathrm{~Hz}, J=2.8$ $\mathrm{Hz}), 3.54(1 \mathrm{H}$, broad dd, $J=12.0 \mathrm{~Hz}, J=3.5 \mathrm{~Hz}), 3.47$ $(1 \mathrm{H}$, broad dd, $J=15.3 \mathrm{~Hz}, J=4.7 \mathrm{~Hz}), 3.42(1 \mathrm{H}, \mathrm{d}, J=$ $13.3 \mathrm{~Hz}), 3.10(1 \mathrm{H}, \mathrm{dd}, J=11.2 \mathrm{~Hz}, J=1.2 \mathrm{~Hz}), 2.92(1 \mathrm{H}$, $\operatorname{td}, J=11.9 \mathrm{~Hz}, J=4.1 \mathrm{~Hz}), 2.91(1 \mathrm{H}, \mathrm{dd}, J=15.3 \mathrm{~Hz}, J=$ $2.0 \mathrm{~Hz}), 2.30(1 \mathrm{H}, \mathrm{dt}, J=13.0 \mathrm{~Hz}, J=3.1 \mathrm{~Hz}), 2.19(1 \mathrm{H}, \mathrm{d}$, $J=11.2 \mathrm{~Hz}), 2.12(1 \mathrm{H}, \mathrm{dq}, J=13.5 \mathrm{~Hz}, J=3.1 \mathrm{~Hz}), 1.70$ $(1 \mathrm{H}, \mathrm{tdd}, J=13.9 \mathrm{~Hz}, J=11.3 \mathrm{~Hz}, J=3.3 \mathrm{~Hz}), 1.48(1 \mathrm{H}$, $\operatorname{td}, J=13.5 \mathrm{~Hz}, J=3.6 \mathrm{~Hz}), 1.13(3 \mathrm{H}, \mathrm{t}, J=7.2 \mathrm{~Hz}) ;{ }^{13} \mathrm{C}$ NMR $\left(\mathrm{CDCl}_{3}, 75.47 \mathrm{MHz}\right) \delta 173.9 ; 144.2 ; 138.5 ; 130.7$; 128.5 (2C); 128.0 (2C); $126.8 ; 118.0 ; 108.1 ; 101.7 ; 101.4$; $61.5 ; 60.6 ; 60.5 ; 57.9 ; 53.5 ; 48.8 ; 45.1 ; 44.4 ; 31.2 ; 28.9$; 14.0 .

(17) Stereochemistry of the products has been fully studied by 2D NMR analysis which is part of F. Liéby-Muller's PhD Thesis, and details will be published in due course.

(18) Although fully reproducible, the origin of the total diastereoselectivity observed in the case of $\mathbf{1 h}$ is not yet clear, and further experimentations and calculations are in progress and will be reported in due course.

(19) Crystallographic data for the structure reported in this paper have been deposited with the Cambridge Crystallographic Data Centre as supplementary publication no. CCDC 264343. Copies of the data can be obtained free of charge on application to CCDC, 12 Union Road, Cambridge CB21EZ, UK (fax: (+44) 1223-336-033; e-mail: deposit@ccdc.cam.ac.uk).

(20) Michael adduct $5 \mathbf{h}$ has been prepared by reaction of $\mathbf{1 h}$ with acrolein 2 , in the presence of Dowex resins. When this 1,5-dicarbonyl compound reacts with amine 3 , same product $4 \mathrm{~h}$ is obtained, as in the one-pot sequence.

(21) Matoba, K.; Shibata, M.; Yamazaki, T. Chem. Pharm. Bull. 1982, 30, 1718.

(22) The presence of MS is crucial since no reaction takes place under simple azeotropic distillation or in the presence of TMOF as dehydrating agent. Moreover, some other heterogeneous catalysts such as basic or acidic alumina, montmorillonite K10 or Dowex ion-exchange resin have been tested in this sequence with very lower efficiency, leading sometimes to decomposition or to the desired product in yields not exceeding $20 \%$. 